\title{
A Rare Presentation of Orbital Cellulitis in a Child with Sturge-Weber Syndrome
}

\author{
Divya Ramamoorthy ${ }^{1}$, Syed Athhar Saqqaf², Aditi Jhamb ${ }^{3}$, Amar Taksande ${ }^{4}$ \\ 1,2,3,4 Department of Paediatrics, Jawaharlal Nehru Medical College, Sawangi Meghe, Wardha, Maharashtra, India.
}

\section{INTRODUCTION}

Sturge - Weber Syndrome (SWS) is an uncommon neuro-oculocutaneous disorder. It is, also known as encephalotrigeminal angiomatosis, which is characterized by angiomas involving the face, choroid, and leptomeninges. Vascular malformation in conjunctiva, choroid, episclera, retina leading to glaucoma is the common ocular manifestation. It is one of the phakomatoses and is often associated with ocular problem, seizures, intellectual disability, and angioma. Here we report a child who has orbital cellulitis of the left eye in a SWS patient.

Rare disorder like SWS, is a congenital neurocutaneous disorder. It is characterised classically by facial capillary haemangioma that is the port wine stain (PWS), which involves the face, forehead and/or scalp along with a choroidal angioma and a venous angioma of the leptomeninges. The incidence of SWS is 1 in 20,000 - 50,000 live births. The systemic implications of SWS are vast and include ophthalmic manifestations, dermatologic, neurologic, and oral manifestations. ${ }^{1-3}$ Here, we are presenting a rare case of Sturge - Weber Syndrome in an eight-year-old male child who presented with orbital cellulitis of the left eye.

\section{PRESENTATION OF CASE}

An 8-year-old male child, known case of Sturge - Weber syndrome with mental retardation, presented with complaints of swelling, pain, watering and redness in left eye for 10 days. He also gave history of similar episode in the past, which was managed conservatively. The swelling in his left eye was insidious in onset, gradually progressive and was associated with watering, pain and discharge. Patient had presented with multiple convulsions for which anti-convulsants drugs was started.

His vitals were temperature of $38.0^{\circ} \mathrm{C}$, a pulse of 94 beats/minute, a blood pressure of $100 / 60 \mathrm{mmHg}$, respiratory rate of 22 breaths/minute, and oxygen saturation on all four limbs was $98 \%$ in room air. General examination revealed mild pallor, icterus was not present and cyanosis or clubbing. There was no evidence of cervical lymphadenopathy. On local examination, patient had tense discharge from his left eye, axial proptosis of his left eye, superficial and deep congestion in conjunctiva (Fig1). Patient's pupil was semi dilated and fixed. Megalocornic oedema and superficial and deep vascularisation was present in cornea and patient also had unilateral total cataract.

\author{
Corresponding Author: \\ Dr. Amar M. Taksande, \\ Department of Paediatrics, \\ Jawaharlal Nehru Medical College, \\ Sawangi Meghe, Wardha - 442004, \\ Maharashtra, India. \\ E-mail: amar.taksande@gmail.com
}

DOI: $10.14260 /$ jemds/2022/63

How to Cite This Article:

Ramamoorthy D, Saqqaf SA, Jhamb A, et al. Rare presentation of orbital cellulitis in a child with Sturge-Weber syndrome. J Evolution Med Dent Sci 2022;11(01):326328, DOI: 10.14260/jemds/2022/63

Submission 20-04-2021,

Peer Review 29-06-2021,

Acceptance 05-07-2021,

Published 31-01-2022.

Copyright (C) 2022 Divya Ramamoorthy et al. This is an open access article distributed under Creative Commons Attribution License [Attribution 4.0 International (CC $B Y 4.0)]$ 
Port wine stain was also present. The higher function and examination of the other cranial nerves was normal. There was no motor and sensory deficit. Normal heart sounds were auscultated on cardiovascular examination and air entry was bilaterally equal on respiratory examination. Her abdomen was soft without hepatosplenomegaly. Laboratory investigations revealed haemoglobin $9.6 \mathrm{~g} / \mathrm{dl}$, WBC $10,100 / \mathrm{mm}^{3}$ platelets $4.15 \mathrm{lakh} / \mathrm{mm}^{3}$, erythrocyte sedimentation rate (ESR) - $120 \mathrm{~mm} / \mathrm{Hr}$ and random blood sugar was $89 \mathrm{mg} / \mathrm{dl}$. Patient also had history of 3 episodes of convulsions for which he was started on anti-convulsants. Magnetic resonance imaging (MRI) of brain with orbit and contrast suggestive of SWS, acute orbital cellulitis and extension of the intra and extra final compartment of the left orbit with thrombosis in the superior sagittal sinus, torcular herophili, distal straight sinus, right transverse sinus and cavernous sinus. The patient was started on oral antibiotics, he was advised for local eye application of antibiotics with symptomatic treatment. Eye's discharge was sent for culture and sensitivity, and in accordance to the report, antibiotics were upgraded. Patient had symptomatic improvement. The child was discharged on oral antibiotics and advised to have a close follow up.

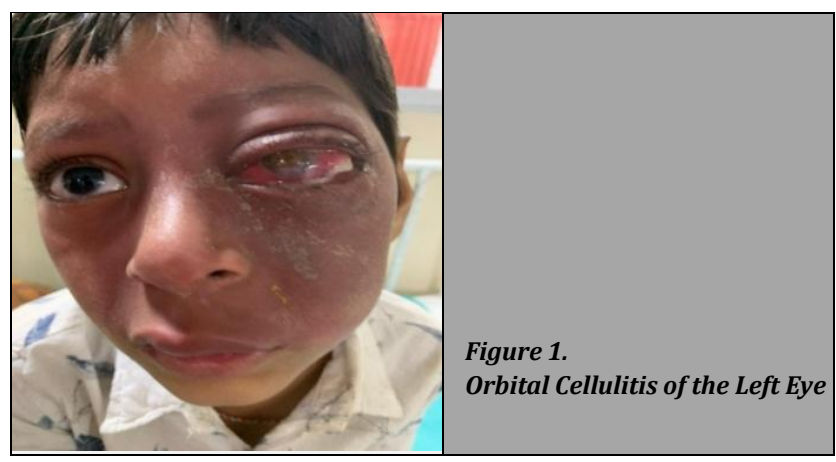

\section{DISCUSSION}

SWS, also known as encephalotrigeminal angiomatosis is the third most common neurocutaneous syndrome after neurofibromatosis and tuberous sclerosis. ${ }^{2-4}$ It is a segmental vascular neurocutaneous syndrome which was described first in 1860 to be associated with facial PWS and buphthalmos by Schirmer. Sturge first gave description regarding presence of PWS with buphthalmos and described naevoid involvement of the brain in 1879. In 1922 and 1923, Weber and Dimitri first reported the early radiological features of SWS respectively. It is caused by a somatic mutation, or as a result of mosaic mutation in a gene GNAQ located on chromosome 9q21. Mutation in GNAQ augments activity in pathway and transmits signals from G protein coupled receptors (GCPR). Mutant constructs were transiently expressed in T293 cells and demonstrated constitutive over activation of downstream pathways. SWS is characterised by a facial capillary malformation (port-wine birthmark) in the V1 distribution (forehead and/or eyelid) of the facial region. In few people, port-wine birthmarks (PWB) are present in the V2 and V3 regions. ${ }^{3-6}$ SWS is presents with group of symptoms and signs characterised by a facial capillary haemangioma (PWB) presented in the periorbital area (upper eyelids), forehead or scalp and it might be present over lower face, trunk, mucosa of mouth and pharynx. It also includes a choroidal and leptomeninges's venous angioma. In approximately $10 \%$ of the cases, facial PWB may be absent.

SWS includes hamartomas of eyes, skin and brain. The typical facial PWS leads to numerous complications of anterior segment of the ocular region and may involve the conjunctiva and eyelids too. Choroidal haemangiomas can cause the visual impairment thorough exudative retinal detachment and macular oedema. In SWS, most common eye manifestation is glaucoma with prevalence rate of $30 \%-70 \% .^{7}$ In our case we reported the orbital cellulitis in the left eye which is very rare. The leptomeningeal angioma involves unilateral, mostly in parieto-occipital region, sometimes entire hemisphere. It is more often uni-hemispheric but may also be bi-hemispheric. Bilateral brain involvement presents with status epilepticus and seizures which become refractory to anti-convulsant, hemiparesis stroke like episodes and developmental delay. Glaucoma and buphthalmos in the ipsilateral eye may be seen in association with the presence of a choroidal angioma. Neurological features never correlated with size and distribution of PWS. It has been hypothesized that developmental abnormality arising in the first trimester of pregnancy could be the SWS. The study done by Comi et al. ${ }^{6}$ reported that proliferation of blood vessels is due to over expression of fibronectin gene. He also suggested that continuous changes may occur within the angioma. It may be due to the evidence that dysregulation of hypoxia - inducible factor alpha gene expression and leads to endothelial turnover in the vessels of SWS, which caused continuous changes to arise within the angioma. The pia mater which involves in the leptomeningeal angioma, mainly in the occipito-parietal region but sometimes also occupies the entire cerebral hemisphere. In angioma, there are tortuous folds of veins and capillaries present in the subarachnoid space. Other vascular finding includes choroid plexus enlargement, deep medullary veins are prominent, cortical veins are either absent or decreased. It is associated with calcification which is progressive and gliosis which is associated with cortical atrophy.

Although calcification and atrophy are imaged by computed tomography (CT), gadolinium enhanced magnetic resonance imaging, a superior technique for detection of extent of the pial angioma, associated vascular anomalies and recent ischemic damage. In addition to the above venous abnormalities, conventional angiography showed stasis and venous circulation. Magnetic resonance angiography has evidently reduced flow in transverse sinuses/jugular veins. Therefore, it is evidence to support the hypothesis that venous stasis is primary abnormality in SWS.

\section{CONCLUSIONS}

Timely detection and intervention can lead to satisfactory surgical outcomes. Our case has some rarely reported features such as orbital cellulitis in SWS young child prompting us to report this case.

Financial or other competing interests: None.

Disclosure forms provided by the authors are available with the full text of this article at jemds.com. 


\section{REFERENCES}

[1] Comi AM. Sturge - Weber syndrome. Handb Clin Neurol 2015;132:157-68.

[2] Shirley MD, Tang H, Gallione CJ, et al. Sturge-Weber syndrome and port-wine stains caused by somatic mutation in GNAQ. N Engl J Med 2013;368(21):1971-9.

[3] Alkonyi B, Chugani HT, Karia S, et al. Clinical outcome in bilateral Sturge-Weber syndrome. Pediatr Neurol 2011;44(6):443-9.

[4] Baselga E. Sturge-Weber syndrome. Semin Cutan Med Surg 2004;23(2):87-98.

[5] Enjolras 0, Riche MC, Merland JJ. Facial port-wine stains and the Sturge-Weber syndrome. Pediatrics 1985;76(1):48-51.
[6] Comi AM, Hunt P, Vawter MP, et al. Increased fibronectin expression in Sturge-Weber syndrome fibroblasts and brain tissue. Pediatr Res 2003;53(5):762-9.

[7] Mantelli F, Bruscolini A, La Cava M, et al. Ocular manifestations of Sturge-Weber syndrome: pathogenesis, diagnosis and management. Clin Ophthalmol 2016;10:871-8.

[8] Oakes WJ. The natural history of patients with SturgeWeber syndrome. Paediatr Neurosurg 1992;18(5-6):28790.

[9] Nakata Y, Yagishita A, Tsuchiya K. Imaging of SturgeWeber syndrome: cranial CT and MR findings. Nihon Igaku Hoshasen Gakkai Zasshi 2004;64(4):210-5. 